\title{
Promoting Socially Just Healthcare Systems: Social Work's Contribution to Patient Navigation
}

\author{
Patricia Louise Desrosiers \\ Gayle Mallinger \\ Tonya Bragg-Underwood
}

\begin{abstract}
Patient navigation is an emerging area of healthcare practice that uses an interdisciplinary and integrated care model designed to reduce health disparities and improve health outcomes. The authors define patient navigation, delineate the alignment of social work competencies with patient navigator requirements, and argue for a clear social work role and presence as patient navigators in interdisciplinary healthcare delivery. Social workers are well-equipped to carry out a variety of patient navigator responsibilities due to their unique skill of social justice advocacy as a macro-level intervention. Through involvement in patient navigation, social work leaders can promote the development of socially just healthcare systems that respect the dignity and worth of all patients.
\end{abstract}

Keywords: Patient navigation; health disparities; social work roles; interdisciplinary teams

Patient navigation is an emerging area of healthcare practice designed to assist patients in negotiating complicated healthcare systems. This patient-centered approach promotes improved health outcomes and diminished health disparities. Specifically, patient navigators (PNs) assist medically needy individuals to overcome barriers to treatment. Thus, navigators are charged with coordinating services, organizing transportation, and arranging for translation and financial support. In addition, the navigator provides emotional support and patient education. Complex patients, including those with multiple diagnoses, diverse cultural backgrounds, or special needs, such as hearing or vision impairments, are often inundated with a variety of helpers. Navigators aim to reduce confusion and frustration for patients.

Consider the fictitious case of Sally, a 70-year-old African American female with high blood pressure who is not having success following her doctor's orders. She first saw Dr. A for a regular checkup which she had avoided for several years. Due to Sally's high blood pressure reading, Dr. A immediately placed her on a blood pressure medication with little discussion about eating right and exercising. When Sally went to fill the prescription, her Medicare did not cover it. Sally is on a fixed income and could not afford the medication. She did not know who to ask for help. She thought Dr. A would be upset if she did not get the medicine. Within 45 days of her checkup, Sally was rushed to the emergency room (ER) after passing out at a family event. This time Sally was assigned a patient navigator, Carol, who had a first visit with Sally while she was in the ER. Carol immediately identified the need for a less expensive, insurance-covered medication and encouraged Sally to discuss this option with the doctor. Sally left the hospital with handouts on coping with

Patricia L. Desrosiers, PhD, LCSW is an Associate Professor, Department of Social Work, College of Health and Human Services, Western Kentucky University, Bowling Green, KY 42101-1039. Gayle Mallinger, PhD, is an Assistant Professor, Department of Social Work, College of Health and Human Services, Western Kentucky University, Bowling Green, KY 42101-1039. Tonya Bragg-Underwood, DNP, APRN-FNP, CNE is an Associate Professor, School of Nursing, College of Health and Human Services, Western Kentucky University, Bowling Green, KY 42101-1039. 
high blood pressure, an appropriate prescription, and Carol's phone number. They had a follow-up appointment two days later at Sally's house. Carol checked on the medication regime, started identifying social supports, and began encouraging healthy eating and exercise goals in collaboration with Sally. Sally has had no additional high blood pressure concerns and has kept all healthcare appointments for the past 60 days. Sally's case study highlights the importance of patient navigation in improving health outcomes and reducing health disparities; however, there is more than just anecdotal evidence.

Since physician Harold Freeman developed the first navigation program in the early 1990s, patient navigation has undergone empirical validation (Freeman, 2012). Patient navigation intervention has been shown to improve health outcomes in patients with chronic health conditions ranging from cancer (Ely et al., 2014; Jean-Pierre et al., 2012) to HIV/AIDS (Sullivan et al., 2015) to diabetes (Esparat et al., 2012). Clients residing in both urban (Nonzee et al., 2012) and rural settings (Ely et al., 2014; Hook, Ware, Siler \& Packer, 2012; Inrig, Tiro, Melhado, Argenbright, \& Craddock Lee, 2014) have benefitted from patient navigation.

Although the genesis of patient navigation revolved around eliminating barriers to treatment for marginalized populations, recent research has demonstrated other benefits as well. Elkin, Shapiro, Snow, Zauber, and Krauskopf (2012) found patient navigation reduces healthcare costs. Increased patient satisfaction and improvements in quality of care have also been reported (Gawande, 2011; Percac-Lima, Ashburner, Bond, Oo, \& Atlas, 2013). In addition, Sullivan and colleagues (2015) found patient navigation services led to diminished health disparities among vulnerable populations.

These positive outcomes have increased the demand for patient navigation; however, there are not enough skilled workers to meet this demand (Nix, Huber, Shapiro, \& Pfiefle, 2016). Social workers already provide effective services in healthcare settings. In fact, there were 146,200 healthcare social workers in the U.S. in 2012 with a projected growth of $37 \%$ by 2022 (U.S. Bureau of Labor Statistics, 2015), making this the third largest area of social work practice. Offering additional training to professionals with overlapping competencies is one potential strategy to increase the number of patient navigators in healthcare settings. With the addition of approximately 12-18 credit hours (the amount in a typical certificate program), social workers can master medical information (including healthcare terminology), electronic medical records, and interdisciplinary team skills. This will prepare them for patient navigation positions in a rapidly changing healthcare industry. Social workers are ethically mandated to realize the value of social justice (National Association of Social Workers [NASW], 2008). Providing leadership, research, and practical services in healthcare settings is one way to realize this value.

The purpose of this conceptual paper is twofold: a) to provide information and guidance for healthcare social workers practicing in medical settings either as patient navigators or alongside them, and b) to encourage the profession to strive towards the social justice mandate through increased leadership, research, and practice in healthcare settings in relation to patient navigation with the goal of improving healthcare outcomes and reducing health disparities. 


\section{Convergence of Social Work and Patient Navigation Best Practices}

In a 2010 position statement on patient navigation, the Oncology Nursing Society, the Association of Oncology Social Work, and the National Association of Social Workers together outlined best practices for social work and nursing professionals involved with patient navigation. These groups asserted that both nursing and social work skills could be enhanced through additional training in patient navigation processes including "conduct[ing] community assessments and the identification and crafting of interventions to resolve systems barriers that interfere with timely access to needed care and services" (Oncology Nursing Society (ONS), Association of Oncology Social Work (AOSW), \& National Association of Social Workers (NASW), 2010, p. 251). They concluded that social workers, nurses, and non-clinically licensed navigators function together in interdisciplinary teams to produce the best patient outcomes (ONS et al., 2010). This position statement suggests that social work is a primary force impacting healthcare systems for the benefit of patients in the current environment, and as such, must continue to take leadership in improving patient care and outcomes.

Hospitals are struggling to deal with Affordable Care Act provisions requiring accountability for patient outcomes, leading to the employment of more patient navigators (Thoms \& Moore, 2012). With a projected growth of the healthcare social work workforce of $27 \%$ between 2012 and 2022, social workers in health settings (including PNs) will be in high demand. As Liechty (2011) points out, social workers have over 100 years of experience in healthcare delivery systems. With such expertise, the mission of the social work profession is congruent with that of patient navigation. Considering social work's values of cultural competency and respect for diversity, social workers are not only ethically obligated to uphold these values, they are also trained to do so during multiple activities throughout their educational process (CSWE, 2015).

\section{Patient Navigation and Council of Social Work Education Competencies}

Prior to the passage and implementation of the Patient Protection and Affordable Care Act of 2010 (ACA, 2010), patient navigation was supported on the federal level. In an effort to improve health outcomes for patients with chronic diseases, including cancer, diabetes, and cardiovascular issues, President Bush signed into law the Patient Navigator Outreach and Chronic Disease Prevention Act of 2005 (Pub. L. 109-18). This law requires patient navigators to facilitate involvement of community organizations to enhance access and decrease barriers to quality healthcare, as well as to provide outreach to vulnerable groups (Pub. L. 109-118).

The ACA makes a single reference to patient navigation in Title III (Improving the Quality and Efficiency of Healthcare), Section 3510. Funding requirements state that core competencies of patient navigators must be defined by the requesting entity. Criteria are more clearly explained in the Training Standards for Navigators and Non-Navigator Assistance Personnel Carrying Out Consumer Assistance Functions under $§ 155.205(d)$ and (e) and 155.210. Among other mandated standards, patient navigation training programs must provide trainees with expertise in meeting the needs of marginalized populations. 
Additionally, Section 1945(h)(7) of the Act defines the "health team" as an interdisciplinary, inter-professional team that requires a variety of healthcare providers, including social workers, to participate in team decision-making. Having social workers with healthcare knowledge on Community Health Teams is expected to enhance the health team functioning; therefore, the social work profession should prioritize healthcare education and training initiatives.

Pratt-Chapman, Willis and Masselink (2014) outline eight domains that in the aggregate comprise competent patient navigation practice. These areas include patient care, knowledge for practice, practice-based learning and improvement, interpersonal and communication skills, professionalism, systems-based practice, inter-professional collaboration, and personal and professional development. Contained within each domain are specific skills that demonstrate the competency. For example, employing active listening, remaining solution-focused with client and action systems, and communicating effectively to build trusting relationships across various cultural and socioeconomic backgrounds are considered key elements of interpersonal and communication skills. Similarly, the ability to sensitively respond to patients of all diversities, including race, religion, and sexual orientation, is part of professional patient navigation. The personal and professional development competence includes identification and effective management of personal and professional conflicts.

Through specialized education and training, social workers are well-equipped to carry out the specified patient navigator duties including public education, information and referral services, and coordination of care (Andrews, Darnell, McBride, \& Gehlert, 2013). Parker and colleagues (2010) categorized tasks of navigators and the social networks with whom they interact. The tasks include navigating patients through a confusing health care system, facilitating patient care, maintaining culturally and linguistically accessible systems of care that reach uninsured and underinsured populations, and carefully documenting these tasks. Patient navigators coordinate services between and among the medical patient and clinical providers, non-clinical staff, supports, and medical records systems. The knowledge, values, and skills needed to be a competent patient navigator mirror those necessary for competent professional social work. Social workers are adept at efficiently managing these tasks and successfully negotiating these systems. Schools of social work are charged with preparing students to deliver competent services to diverse populations (CSWE, 2015). The values of self-determination, empowerment, and collaboration with client systems are central to the profession of social work (Scheyett \& Diehl, 2004).

Social work accreditation standards promote competency-based education (CSWE, 2015). Upon graduation, social work students are expected to effectively demonstrate a number of practice behaviors related to each competency. For example, accredited schools of social work ensure that students successfully demonstrate an understanding of how diversity and structural exclusions influence experiences of marginalized populations. Students are also expected to recognize how their personal values may be in conflict with professional social work values and demonstrate use of self-reflection to manage personal values and uphold professional values and ethics. Further, social work students are required 
to be skilled in collaboration and advocacy to best serve diverse client systems. All of these competencies are important to patient navigation positions as well.

Table 1 displays the social work competencies (CSWE, 2015) side-by-side with professional or non-clinically licensed patient navigator competencies (Patient Centered Education \& Research Institute [PCERI], 2015). It is notable that each of the five core competencies for patient navigators corresponds to at least one social work competency. This further demonstrates the close relationship between social work competencies and PN competencies.

Table 1. Comparison of Social Work Competencies and Patient Navigation Competencies

\begin{tabular}{|c|c|}
\hline \multicolumn{2}{|c|}{ Competencies } \\
\hline Social Work (CSWE, 2015) & Professional Patient Navigator (PCERI, 2015) \\
\hline $\begin{array}{l}\text { Comp. 1: Demonstrate ethical and } \\
\text { professional behavior }\end{array}$ & Core I: Professional knowledge \\
\hline $\begin{array}{l}\text { Comp. 2: Engage diversity and difference } \\
\text { in practice }\end{array}$ & Core II: Patient services \\
\hline $\begin{array}{l}\text { Comp. 3: Advance human rights and } \\
\text { social, economic, and } \\
\text { environmental justice }\end{array}$ & Core V: System-based practice \\
\hline $\begin{array}{l}\text { Comp. 4: Engage in practice-informed } \\
\text { research and research-informed } \\
\text { practice }\end{array}$ & Core III: Evidence-based delivery \\
\hline Comp. 5: Engage in policy practice & Core V: System-based practice \\
\hline $\begin{array}{l}\text { Comp. 6: Engage with individuals, } \\
\text { families, groups, organizations, } \\
\text { and communities }\end{array}$ & $\begin{array}{l}\text { Core II: Patient services } \\
\text { Core IV: Interpersonal communication and } \\
\quad \text { collaboration skills } \\
\text { Core V: System-based practice }\end{array}$ \\
\hline $\begin{array}{l}\text { Comp. 7. Assess individuals, families, } \\
\text { groups, organizations, and } \\
\text { communities }\end{array}$ & $\begin{array}{l}\text { Core II: Patient services } \\
\text { Core IV: Interpersonal communication and } \\
\text { collaboration skills } \\
\text { Core V: System-based practice }\end{array}$ \\
\hline $\begin{array}{l}\text { Comp. 8: Intervene with individuals, } \\
\text { families, groups, organizations, } \\
\text { and communities }\end{array}$ & $\begin{array}{l}\text { Core II: Patient services } \\
\text { Core IV: Interpersonal communication and } \\
\quad \text { collaboration skills } \\
\text { Core V: System-based practice }\end{array}$ \\
\hline $\begin{array}{l}\text { Comp. 9: Evaluate practice with } \\
\text { individuals, families, groups, } \\
\text { organizations, and communities }\end{array}$ & $\begin{array}{l}\text { Core II: Patient services } \\
\text { Core IV: Interpersonal communication and } \\
\text { collaboration skills } \\
\text { Core V: System-based practice }\end{array}$ \\
\hline
\end{tabular}

\section{Definition of Patient Navigation}

The definition of patient navigation is not firmly established. The needs of health and behavioral health organizations vary. The definitions of patient navigation at various institutions reflect the particular needs of the organization. Some definitions are task focused, while others focus on goals such as reducing barriers to care (Thoms \& Moore, 2012). Thus, there is no universally accepted definition of patient navigation (Gunn, Clark, 
Battaglia, Freund, \& Parker, 2014). Consequently, there are multiple definitions of patient navigation in use across the United States.

Gunn and colleagues (2014) indicate how differences in program level principles occur as a result of interactions between patient navigators and varying professional groups within each specific patient navigation program. As changes in the role of patient navigation occur, the professional roles within each program change. The different levels of patient navigation in healthcare settings (i.e., non-clinically licensed (PN), clinically licensed (CPN), or volunteer [VN]) alter the navigators' role further. For example, if a CPN is present in the setting, this navigator may focus on advocating for change in system-level barriers and supervising and training PNs and VNs. At the same time, PNs focus on overcoming individual-level barriers and assisting patients in problem-solving the day-today difficulties of following recommended treatments, identifying resources, and understanding medical terms and treatments. At the same time, VNs may alleviate barriers to care through transporting patients to appointments, encouraging patients to attend appointments through reminder phone calls, and identifying strengths and support systems. Multiple patient navigator levels require a coordinated patient navigation system.

It is important to establish unique definitions for each patient navigation position in order to reduce confusion for patients and multidisciplinary team members. A clear scope of practice and defined levels of skill were missing in many of the programs reviewed by Gunn et al. (2014). These authors provide a firm definition thereby preventing the usurping of the patient navigation role by other professional groups. Until there is agreement on the role and scope of practice, patient navigation programs will continue to struggle with implementation of these unique roles.

While not offering a specific definition, Freeman (2012) recently established nine principles and standards of patient navigation that can be used as a starting point. Freeman's principles are summarized as the following:

a) "Patient navigation is a patient-centered health care service delivery model" focused on assisting patients to move in a timely way through the "complex health care continuum " (p. 1616).

b) Patient navigation integrates a fragmented health care system for the individual patient.

c) One patient navigation "core function... is the elimination of barriers to timely care" through a "one-on-one relationship between the navigator and the patient "(p. 1616).

d) Clear scope of practice should be defined for PNs, and PNs should be integrated into the health care team.

e) Patient navigation services should be cost-effective, and the PN must have appropriate training and skill for the patient treatment phase.

f) "...A spectrum of navigation..." ranging from trained lay navigators "to services that require navigators who are professionals, such as nurses and 
social workers" should be effectively utilized so that appropriate providers are assigned at appropriate times in the patient treatment process (p. 1616).

g) Each system of care should define the start and end of patient navigation.

h) The process of patient navigation should operate across disconnected systems of care for the benefit of patients.

i) Patient Navigation systems require coordination, and one coordinator should oversee all phases of navigation activity within the system.

Table 2 includes Freeman's (2012) principles that are the basis for the proposed definition for non-clinically licensed patient navigation. The proposed definition emphasizes that multiple skill levels of navigation are required at different points in the treatment process.

Table 2. Aspects of Non-Clinically Licensed Patient Navigation

\begin{tabular}{|c|c|c|c|}
\hline & $\begin{array}{c}\text { Freeman's } \\
\text { Principles } \\
\text { (2012) } \\
\end{array}$ & $\begin{array}{c}\text { Pratt- } \\
\text { Chapman et } \\
\text { al. }(2014)\end{array}$ & $\begin{array}{l}\text { PCERI } \\
(2015) \\
\end{array}$ \\
\hline \multicolumn{4}{|l|}{ Individual Level Aspects } \\
\hline Patient-centered care & $\sqrt{ }$ & $\sqrt{ }$ & $\sqrt{ }$ \\
\hline Integration of a fragmented system of care & $\sqrt{ }$ & $\sqrt{ }$ & $\sqrt{ }$ \\
\hline Elimination of barriers to timely care & $\sqrt{ }$ & $\sqrt{ }$ & \\
\hline Resource identification & & & $\sqrt{ }$ \\
\hline Inter-professional collaboration & $\sqrt{ }$ & $\sqrt{ }$ & $\sqrt{ }$ \\
\hline Knowledge of healthcare terms and treatments & & $\sqrt{ }$ & $\sqrt{ }$ \\
\hline Strong communication skills & & $\sqrt{ }$ & $\sqrt{ }$ \\
\hline Ethical knowledge & & $\sqrt{ }$ & $\sqrt{ }$ \\
\hline Professional presentation of self & & $\sqrt{ }$ & $\sqrt{ }$ \\
\hline Self-care knowledge & & $\sqrt{ }$ & \\
\hline Helping patients follow preferred treatment protocols & & & $\sqrt{ }$ \\
\hline Navigate across disconnected systems & $\sqrt{ }$ & & $\sqrt{ }$ \\
\hline Knowledge of PN role & $\sqrt{ }$ & & $\sqrt{ }$ \\
\hline Cultural sensitivity & & & $\sqrt{ }$ \\
\hline \multicolumn{4}{|l|}{ Program Level Aspects } \\
\hline Defined level of skill & $\sqrt{ }$ & & $\sqrt{ }$ \\
\hline Defined beginning and end of navigation & $\sqrt{ }$ & $\sqrt{ }$ & \\
\hline Clear scope of practice/roles for all PN levels & $\sqrt{ }$ & $\sqrt{ }$ & $\sqrt{ }$ \\
\hline System improvement & & $\sqrt{ }$ & $\sqrt{ }$ \\
\hline Cost-effective & $\sqrt{ }$ & & \\
\hline Coordinated patient navigation system & $\sqrt{ }$ & $\sqrt{ }$ & \\
\hline
\end{tabular}

The George Washington Cancer Institute developed eight core competencies to be used in developing non-clinically licensed patient navigation positions (Pratt-Chapman et al., 2014). There is some overlap between these eight core competencies and Freeman's nine principles (Freeman, 2012) including patient-centered care and interprofessional collaboration; however, these competencies are more specific and skills-based than Freeman's principles. Competencies not mentioned by Freeman (2012) or Gunn et al. (2014) include knowledge of healthcare terms and treatments, strong communication skills, ethical and professional presentation of self, and self-care (Pratt-Chapman et al., 2014). 
The Patient Centered Education and Resource Institute (PCERI, 2015) has emerged with the goal of certifying patient navigators to make sure that they are able to demonstrate a basic skill level that will facilitate patient success. The Institute lists one additional competency of "helping patients follow preferred treatment protocols" (PCERI, para. 3) which would enhance the definition. Considering these various competencies leads to the following definition:

Patient navigation: Patient-centric interventions (undertaken by ethical professionals with strong communication and self-care skills plus knowledge of medical terminology and treatments) spanning professions and organizations that assist patients in removing barriers to accessing and utilizing care and in identifying resources that exist in a fragmented and disconnected healthcare system with the goal of successfully navigating and improving the continuum of care (Freeman, 2012; Gunn et al., 2014; PCERI, 2015; Pratt-Chapman et al., 2014).

This working definition is inclusive of the skills, knowledge, values, and behaviors currently used by practicing lay patient navigators and the bodies that seek to certify them. This definition provides a starting point to examine the intersection of patient navigation and social work competencies. See Table 2 for the range of individual and program level aspects included in this definition.

In the current U.S. healthcare context, both social workers and nurses are functioning in the role of patient navigator. This is typical because both professions possess most of the required skills for patient navigation. For example, while licensed bachelor-prepared nurses are knowledgeable regarding medical terminology and disease processes, licensed bachelor-prepared social workers do not leave social work programs with detailed knowledge of medical terms and disease processes. While licensed BSW-level social workers are skilled in community assessment as well as advocating for systems change and social justice, licensed bachelor-prepared nurses typically do not possess that knowledge. Optimally, both professions are working together on an interdisciplinary team to enhance patient outcomes (ONS et al., 2010); however, when that is not the case, and one or the other of these professionals serves in the role of a non-clinically licensed patient navigator, adherence to this definition of the non-clinically based patient navigator serves to differentiate the non-clinical patient navigator role from that of a clinically licensed social worker or a licensed nurse practitioner.

\section{Patient Navigation: $C P N$ versus $P N$}

From a social work perspective, a clinically licensed patient navigator (CPN) possesses a clinical social work skill set in addition to the case management skill set of a nonclinically licensed patient navigator (PN). For example, a clinically licensed social work patient navigator (with an MSW and a clinical license) may function as a therapist in addition to functioning as a patient navigator. When that is the case, both roles must be clearly defined in order to provide the most cost-efficient, coordinated system of care. If the majority of a CPN's work tasks could be completed by a PN, it would make financial sense to hire a PN instead. If half of a CPN's work tasks are related to a clinical role and supervision, then it would be financially prudent to continue a dual position. A social 
worker with a non-clinical license can function as a non-clinically licensed social worker/patient navigator $(\mathrm{PN})$.

\section{Models of Patient Navigation}

Several models of patient navigation have been explored in the literature. Based on strong alignment with the social work perspective, we describe two models - the Freeman Model and the Transformation for Health Framework (Esparat et al., 2012). These models serve to highlight the fit between social work and patient navigation.

\section{Freeman's Model}

Freeman pioneered the concept of patient navigation in 1990 to use the "critical window of opportunity... between an abnormal finding to the point of resolution of the finding by diagnosis and treatment" (Freeman Patient Navigation Institute, 2015, para 1). This concept has since been expanded to include patient navigation across the healthcare continuum from prevention to end-of-life palliative care. Freeman's model relies on nine principles that focus on removing barriers to medical care. These frequently include financial, communication, medical system, and psychological barriers in addition to barriers such as lack of transportation and child care. Barriers are overcome through oneon-one guidance and assistance to individuals as they move through the continuum of healthcare. PNs bridge the divides in a disconnected healthcare system where patients sometimes get lost (Freeman, 2012).

In Freeman's face-to-face model, lay navigators (those with training and experience but no professional degree) and professional navigators, PNs and CPNs (nurses and social workers), assist patients according to their level of experience and training. This may lead to role confusion as various levels of navigators are working together. Clarifying roles and maintaining dialogue among team members is necessary to avoid duplication of services and to ensure workers are providing services at their appropriate level of expertise.

\section{Transformation for Health Framework}

As previously discussed, it is possible to divide patient navigation roles into PN and CPN groupings dependent upon contextual needs. Esparat et al.'s (2012) intervention adds another level called a Community Health Worker (CHW). CHWs are associate-level nurses who are trained and supervised by a CPN. Employing CHWs indigineous to the patient's home community is key. CHWs provide training and support to patients struggling with chronic health conditions, including hypertension, diabetes, and asthma (Esparat et al., 2012).

In Esparat et al's (2012) Tranformation for Health Framework, patients move through four phases whereby they are able to overcome oppressive conditions that may prevent them from gaining the full benefit of the healthcare system. In the first phase, cognition, critical consciousness is developed as patients comprehend the nature of their conditions and the ways in which their lives may be impacted. Ideally, patients ultimately realize that they can control their health conditions. The CHW facilitates this through interactions which balance unequal power relationships between healthcare providers and the 
healthcare receiver. In the second phase, intention, the individual's motivational system is activated by the critical consciousness awakened in the previous phase. The individual makes the decision to change behaviors and elements of their lifestyle that affect the progression of the chronic disease. The third phase, decision, is where the individual actually makes changes in behavior that promote self-management of negative conditions. During the final phase, transformation, the patient is assisted with development of chronic disease management skills. The patient receives support in transforming into a person in charge of their own health status. Esparat and colleagues found the use of this face-to-face model led to statistically significant changes in clinical biomarkers such as reduced blood pressure and HgbA1c, as well as reducing hospital admissions for asthma.

It is notable that Esparat et al. (2012) recommended a PN/CPN position to provide supervision to $\mathrm{CHWs}$, advocate for systems change, and complete program evaluations. If changes to the position or system were needed, the PN/CPN manage those tasks. Esparat et al. (2012) recommends that a nurse be hired in this position; however, a social worker would also fit. In this particular setting, due to the use of associate-level nurses being used as CHW/PNs, it may reduce role tension to use a nurse PN; however, the use of a social worker in the supervisory position would provide an opportunity for an inter-disciplinary team as mandated by the ACA of 2010 (ACA; Pub. L. 111-148). This is also consistent with recommendations from a patient navigation position statement jointly produced by the ONS et al. (2010) in which navigation practiced by trained non-clinical or volunteer staff may occur under the supervision of a nurse or a social worker. These models are good examples of patient navigation, and both are consistent with social work values and ethics.

\section{Patient Outcomes with Patient Navigation}

Patient navigation began with Freeman's foray into its usefulness for cancer patients (Freeman, 2012). Over the past twenty years, multiple studies have demonstrated the usefulness of PNs and CPNs as a best practice for encouraging cancer screening and treatment (Braschi, Sly, Singh, Villagra, \& Jandorf, 2014; Ely et al., 2014; Inrig et al., 2014; Nonzee et al., 2012). However, the success of patient navigation across the United States has moved beyond solely cancer-related ailments. Research demonstrates that PN services have successfully increased adherence to preferred treatment protocols among diverse patient populations (Dignan et al., 2005; Esperat et al., 2012; Gawande, 2011).

All of the previous research studies explored face-to-face patient navigation services with the exception of two: Dignan et al. (2005) and Loiselle et al. (2013). A virtual environment was the chosen environment for navigation in Loiselle et al.'s (2013) study. A website with cancer information was provided for newly diagnosed cancer patients, and the patients reported via telephone that they appreciated the resource because they could limit the amount of information they received at one time and they could search for answers at times when phone calls to a provider were infeasible (i.e., late at night). Dignan and colleagues (2005) compared face-to-face and telephonic navigation to increase mammogram screenings for urban Native American women and found no difference in outcomes. 
In their study of telephonic patient navigation, Dignan et al. (2005) determined that transient populations such as Native American women would frequently not complete the intervention due to not having a working phone when on the reservation where they periodically resided. The digital divide is real with approximately $48.5 \%$ of households with incomes less that $\$ 25,000$ per year (as opposed to between $69-94.9 \%$ for those households earning more than $\$ 25,000$ per year) and only $61.3 \%$ of Black and $58.2 \%$ of Native American households (as opposed to $77.4 \%$ of White and $86.6 \%$ of Asian households) having internet access at home (Rainie, 2015). Over a third (35\%) of adults aged 65 or older do not use the internet (Rainie, 2015). Providing online services that clients cannot access or do not access cannot improve outcomes. Thus, context is important when determining the patient navigation model for a particular area or population.

The use of PNs and CPNs to support patients dealing with a multitude of chronic health conditions has proliferated in the past five to ten years as successes have been realized. Women of color coping with HIV/AIDS in North Carolina (Sullivan et al., 2015), refugees in Boston struggling with obtaining regular breast cancer screening (Percac-Lima et al., 2013), and patients of Mexican heritage in Texas struggling with hypertension, diabetes, and asthma (Esperat et al., 2012) have all realized successful outcomes with the support of patient navigation services.

\section{Discussion}

It may seem puzzling that healthcare systems developed a job title of "Patient Navigator" when the competencies necessary for this position are so closely aligned with that of "Social Worker." Healthcare social workers in particular have been providing effective services to patients in clinics, hospitals, and other medical settings for many years. With a workforce approaching 150,000, there is strong evidence for the presence of healthcare social workers. With a projected demand for an additional 39,200 healthcare social workers by the year 2022, there is a great need for well-trained social workers to work in healthcare settings (U.S. Bureau of Labor Statistics, 2015). Some may argue that the current shortage of healthcare social workers is partially responsible for the recent development of patient navigation positions and programs.

Despite some overlap, there are differences between social work competencies and those of a patient navigator ranging from knowledge to professional skills to ethics. Darnell (2007) specifically discussed the social work value of promoting patient self-determination as a critical dimension "...that is largely absent from the public discussion about patient navigation..." (p. 83). Knowledge differences include knowledge of healthcare terminology, specific disease and illness processes, and medical treatments (PCERI, 2015). As any oncology social worker can attest, learning those terms happens with time; however, if they were taught prior to the social worker entering the healthcare setting, this would reduce training time. With education and experience, other professions will become more aware of the valuable contributions that social workers make to healthcare teams.

Skill differences include the competencies of advancing social justice, engaging diversity and difference, engaging in policy practice, and a systems perspective that requires simultaneous attention to micro, mezzo, and macro practice (CSWE, 2015). Davis, 
Darby, Likes, and Bell (2009) report that oncology social workers are natural leaders with regard to decreasing health disparities due to their professional values, training, and skills. One specific social work competency requires demonstrating ethical and professional behavior by adhering to the NASW (2008) Code of Ethics (CSWE, 2015). Should a social worker fail to uphold these standards, a client has recourse options. Without licensure or any specific governance of competencies, vulnerable clients in healthcare settings have little protection when their patient navigation provider is ineffective, under-performing, or fails to practice ethically.

As part of a college-wide team at Western Kentucky University, we developed an interdisciplinary patient navigator certificate program in order to prepare students from various disciplinary backgrounds for this career option. Social work, nursing, public health, and health information management programs collaborated in developing the interdisciplinary training program. Through the use of existing courses, undergraduate students from multiple majors participating in the certificate program are being crosstrained in other disciplines to ensure that all patient navigation competencies are met. Initiatives such as this can help meet the increasing need for competent PNs while ensuring that the particular domains of the various professions are understood and respected.

Schools of social work are already successfully preparing healthcare social workers. Patient navigation provides an opportunity for social workers to facilitate positive changes on the micro, mezzo, and macro levels. Governmental mandates require each Cancer Center to employ a PN (Pub. L. 109-18). Further, healthcare clients are assigned social workers as part of their healthcare team (ACA, 2010). The increased needs for PNs in addition to other healthcare social work positions necessitates that social workers are increasingly knowledgeable in these areas and involved as leaders in shaping these contexts.

Rishel (2015) recommends establishing a prevention-focused integrative approach to social work practice as a way to "effectively function and provide leadership in the new era of health care" (p. 125). According to Rishel (2015), this approach "integrates micro, mezzo, and macro practice efforts across service systems and with allied health and social service professionals to effectively and efficiently address major problems of living within the environmental context" (p. 127) which in this case dovetails well with the position of PN. Adopting an approach such as this in the creation of patient navigation systems and processes is increasingly considered best practice and is consistent with the mandates of the Patient Protection and Affordable Care Act.

Specifically, social workers in micro practice can provide services to medically needy individuals who are at risk. Those specifically in the role as patient navigators have the skills needed to coordinate services, provide support, and advocate for individual clients. On a mezzo level, social work navigators work with family members and can develop educational and support groups for clients. On a macro level, social workers have the advocacy skills to promote policy changes including securing funding for workforce development and regulation of patient navigators. Schools of social work can work in tandem with other disciplines to develop interdisciplinary programs to meet this growing workforce need. 


\section{Implications for Practice and Research}

While there are many compelling reasons social workers should be involved in patient navigation, the most important is the benefit to clients. Improving healthcare outcomes and reducing health disparities in healthcare access and utilization are consistent with the social work value of social justice. Patient navigation has consistently facilitated improved patient outcomes. Research questions remain, and development of research projects aimed at determining variance in patient outcomes is necessary. Do healthcare outcomes vary by educational perspective of the patient navigation provider? Which competencies impact health care outcomes, and how? What level of educational preparation is ultimately most effective for each health care challenge? Additional projects to assess the potential role confusion that occurs in all professions doing patient navigation work as well as the unique benefits of social worker PNs on healthcare teams are needed. These lines of inquiry will further inform the utility of social work involvement in patient navigation.

Providing leadership to patient navigation programs in healthcare settings should be urgently undertaken by social workers individually and as a profession. Social work leaders can facilitate the development of socially just healthcare systems that respect the dignity and worth of all patients. The social justice mandate found in our professional Code of Ethics (NASW, 2008) can be used to improve PN practices. The Standards for Practice in Healthcare Settings (NASW, 2005) are guiding principles for the specialized knowledge, skills, values, and method requirements of healthcare social workers, and initiatives such as Social Work HEALS demonstrate that the social work profession is taking these specialized requirements seriously (CSWE, 2015). Continued responsiveness to the current healthcare context indicates social work should be involved in the training of not only additional healthcare social workers, but also social workers with the additional patient navigation competencies who may be dually licensed. Meeting the growing healthcare needs of diverse communities while reducing health disparities is the ultimate benefit of social work involvement in patient navigation.

\section{References}

Affordable Care Act Title III. (2010). (Improving the Quality and Efficiency of Health Care), § $3510 \S \S 155.205(\mathrm{~d})$ and (e) \& $155.210 \S \S 1945(\mathrm{~h})(7)$

Andrews, C. M., Darnell, J. S., McBride, T. D., \& Gehlert, S. (2013). Social work and implementation of the Affordable Care Act. Health Care and Social Work, 38(2), 5571.

Braschi, C. D., Sly, J. R., Singh, S., Villagra, C., \& Jandorf, L. (2014). Increasing colonoscopy screening for Latino Americans through a patient navigation model: A randomized clinical trial. Journal of Immigrant Minority Health, 16, 934-940. doi:https://doi.org10.1007/s10903-013-9848-y

Council on Social Work Education [CSWE]. (2015). Educational policy and accreditation standards for baccalaureate and master's social work programs. Washington, DC: CSWE. 
CSWE. (2015). Social Work HEALS: Social Work Healthcare Education and Leadership Scholars. Washington, DC: CSWE. Retrieved from http://www.cswe.org/CentersInitiatives/ScholarshipsandFellowships/79270.aspx

Darnell, J. S. (2007). Patient navigation: A call to action. Social Work, 52(1), 81-83.

Davis, C., Darby, K., Likes, W., \& Bell, J. (2009). Social workers as patient navigators for breast cancer survivors: What do African American medically underserved women think of this idea? Social Work in Health Care, 48(6), 561-578. doi:https://doi.org10.1080/00981380902765212

Dignan, M. B., Burhansstipanov, L., Hariton, J., Harjo, L., Rattler, J., Lee, R., \& Mason, M. (2005). A comparison of two Native American navigator formats: Face-to-face and telephone. Cancer Control, 12(Supplement 2), 28-33.

Elkin, E. B., Shapiro, E., Snow, J. G., Zauber, A. G., \& Krauskopf, M. S. (2012). The economic impact of a patient navigator program to increase screening colonoscopy. Cancer, 118, 5982-5988. doi:https://doi.org10.1002/cncr.27595

Ely, G. E., White, C., Jones, K., Feltner, F., Gomez, M., Shelton, B., . . Dignan, M. (2014). Cervical cancer screening: Exploring Appalachian patients' barriers to follow-up care. Social Work in Health Care, 53, 83-95. doi:https://doi.org10.1080/00981389.2013.827149

Esperat, M. C., Flores, D., McMurry, L., Feng, D., Song, H., Billings, L., \& Masten, Y. (2012). Tranformacion para salud: A patient navigation model for chronic disease self-management. Online Journal of Issues in Nursing, 17(2), 1. doi:https://doi.org10.3912/OJIN.Vol17No02Man02

Freeman, H. P. (2012). The origin, evolution, and principles of patient navigation. Cancer Epidemiology Biomarkers Prevention Focus, 21(10), 1614-1617.

Freeman Patient Navigation Institute. (2015). Our model. Retrieved from http://www.hpfreemanpni.org/ourmodel/?PHPSESSID=d25940662490479936b31b897fe455b6

Gawande, A. (2011). The Hot Spotters-Can we lower medical costs by giving the neediest patients better care? The New Yorker, 86(45), 40-51.

Gunn, C. M., Clark, J. A., Battaglia, T. A., Freund, K. M., \& Parker, V. A. (2014, October). An assessment of patient navigator activities in breast cancer patient navigation programs using a nine-principle framework. Health Services Research, 49(5), 1555-1577. doi:https://doi.org10.1111/1475-6773.12184

Hook, A., Ware, L., Siler, B., \& Packard, A. (2012, July). Breast cancer navigation and patient satisfaction: Exploring a community-based patient navigation model in a rural setting. Oncology Nursing Forum, 39(4), 379-385. doi:https://doi.org10.1188/12.ONF.379-385

Inrig, S., Tiro, J., Melhado, T., Argenbright, K., \& Craddock Lee, S. (2014). Evaluating a de-centralized regional delivery system for breast cancer screening and patient 
navigation for the rural underserved. Texas Public Health Association Journal, 66(2), 25-34.

Jean-Pierre, P., Fiscella, K., Winters, P. C., Post, D., Wells, K. J., McKoy, J. M., . . The Patient Navigation Group. (2012, June 17). Psychometric development and reliability analysis of a patient satisfaction with interpersonal relationship with navigator measure: A multi-site patient navigation research program study. Psycho-Oncology, 21, 986-992. doi:https://doi.org10.1002/pon.2002

Liechty, J. M. (2011). Health literacy: Critical opportunities for social work leadership in health care and research. Health and Social Work, 36(2), 99-107.

Loiselle, C. G., Peters, O., Haase, K. R., Girouard, L., Korner, A., Wilier, D., \& Fitch, M. (2013). Virtual navigation in colorectal cancer and melanoma: An exploration of patients' views. Support Care Cancer, 21, 2289-2296. doi:https://doi.org10.1007/s00520-013-1771-1

National Association of Social Workers [NASW]. (2005). NASW standards for social work practice in health care settings. Washington, DC: NASW.

NASW. (2008). NASW Code of Ethics. Washington, DC: Author.

Nix, A. T., Huber, J. T., Shapiro, R. M. \& Pfiefle, A. (2016). Examining care navigation: Librarian participation in a team-based approach. Journal of Medical Library Association, 104 (2), 131-137.

Nonzee, N. J., McKoy, J. M., Rademaker, A. W., Byer, P., Luu, T. H., Liu, D., . . . Simon, M. A. (2012). Design of a prostate cancer patient navigation intervention for a Veterans Affairs hospital. Health Services Research, 12(340), 1-9. doi:https://doi.org10.1186/1472-6963-12-340

Oncology Nursing Society, The Association of Oncology Social Work, \& The National Association of Social Workers. (2010). Oncology Nursing Society, the Association of Oncology Social Work, and the National Association of Social Workers joint position on the role of oncology nursing and oncology social work in patient navigation. Oncology Nursing Forum, 37(3), 251-252.

Parker, V. A., Clark, J. A., Leyson, J., Calhoun, E., Carroll, J. K., Freund, K. M., \& Battaglia, T. A. (2010). Patient navigation: Development of a protocol for describing what navigators do. Health Services Research, 45(2), 514-531. doi:https://doi.org10.1111/j.1475-6773.2009.01079.x

Patient Centered Education \& Resource Institute. (2015). Professional patient navigator competencies. Retrieved from http://patient-institute.org

Patient Navigator Outreach and Chronic Disease Prevention Act of 2005, Pub. L. 109-18, 119 Stat. 340 (2005).

Patient Protection and Affordable Care Act of 2010, Pub. L. 111-148. (2010).

Percac-Lima, S., Ashburner, J. M., Bond, B., Oo, S. A., \& Atlas, S. J. (2013). Decreasing disparities in breast cancer screening in refugee women using culturally tailored 
patient navigation. Journal of General Internal Medicine, 28(11), 1463-1468. doi:https://doi.org10.1007/s11606-013-2491-4

Pratt-Chapman, M., Willis, L., \& Masselink, L. (2014). Core competencies for nonclinically licensed patient navigators. Washington, DC: The George Washington University Cancer Institute Center for the Advancement of Cancer Survivorship, Navigation and Policy.

Rainie, L. (2015). Digital divides 2015. Retrieved from Pew Research Center at http://www.pewinternet.org/2015/09/22/digital-divides-2015/

Rishel, C. (2015). Establishing a prevention-focused integrative approach to social work practice. Families in Society, 96(2), 125-132.

Scheyett, A., \& Diehl, M. J. (2004). Walking our talk in social work education: Partnering with consumers of mental health services. Social Work Education, 23(4), 435-450.

Sullivan, K. A., Schultz, K., Ramaiya, M., Berger, M., Parnell, H., \& Qunlivan, E. B. (2015). Experiences of women of color with a nurse patient navigation program for linkage and engagement in HIV care. AIDS Patient Care and STDs, 29(Supplement 1), s49-s54. doi:https://doi.org10.1089/apc.2014.0279

Thoms, E., \& Moore, D. (2012, December). The emerging field of patient navigation: A golden opportunity to improve healthcare. The Center of Health Affairs. Retrieved 2015, from www.chanet.org

United States Bureau of Labor Statistics. (2015). Occupational employment and wages, May 2014: 21-1022. Healthcare Social Workers. Retrieved from http://www.bls.gov/oes/current/oes211022.htm

\section{Author note:}

Address correspondence to: Patricia Desrosiers, Department of Social Work, Western Kentucky University, Academic Complex Room 113B, 1906 College Heights

Blvd\#11039, Bowling Green, KY 42101-1039, 270-745-4557

patricia.desrosiers@wku.edu 